\title{
Workforce Integration of New Graduate Nurses: Evaluation of a Health Human Resources Employment Policy
}

\author{
Intégration de la main-d'œuvre chez les nouveaux \\ diplômés en soins infirmiers : évaluation d'une politique \\ d'emploi dans les ressources humaines en santé
}

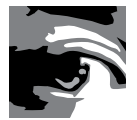 \\ ANDREA BAUMANN, RN, PHD \\ Associate Vice President, International Health, Faculty of Health Sciences, McMaster University \\ Director, Nursing Health Services Research Unit (McMaster University Site) \\ Hamilton, ON \\ MABEL HUNSBERGER, RN, PHD \\ Associate Professor, School of Nursing, McMaster University \\ Research Associate, Nursing Health Services Research Unit (McMaster University Site) \\ Hamilton, ON \\ MARY CREA-ARSENIO, MSC \\ Research Coordinator, Nursing Health Services Research Unit (McMaster University Site) \\ Hamilton, ON
}

\begin{abstract}
Historically, economic changes have negatively affected the nursing workforce in Ontario. The trend towards part-time and casual employment emerged from healthcare restructuring in the 1990s. The severe acute respiratory syndrome (SARS) outbreak in 2003 alerted the Ontario government to the issue of part-time and casual nursing. In 2007, the Nursing Graduate Guarantee (NGG), a health human resources employment policy, was developed as a financial incentive for employers to hire and mentor new graduate nurses for a six-month period. The purpose of this study was to examine facilitators and barriers to policy implementation and assess the
\end{abstract}


impact of the NGG on full-time employment and workforce integration of new graduate nurses in Ontario. A mixed-methods approach was used and included surveys, interviews and focus groups. Results indicated that full-time employment of new graduate nurses increased during the study period and that mentorship facilitated workforce integration of new graduate nurses.

\section{Résumé}

Traditionnellement, les changements économiques ont eu un impact négatif sur la maind'ouvre infirmière en Ontario. La tendance vers les emplois à temps partiel ou temporaires vient de la restructuration des services de santé dans les années 1990. L'éclosion du syndrome respiratoire aigu sévère (SRAS) en 2003 a éveillé l'attention du gouvernement de l'Ontario sur la question des emplois infirmiers à temps partiel et temporaires. En 2007, il créait la Garantie d'emploi pour les diplômés en soins infirmiers, une politique d'emploi visant à offrir des incitatifs financiers aux employeurs pour embaucher de nouveaux diplômés en soins infirmiers et agir comme mentors auprès d'eux pendant une période de six mois. L'objectif de cette étude était d'examiner les facteurs favorisant ou faisant obstacle à la mise en œuvre de la politique et d'évaluer son impact sur l'emploi à temps plein et l'intégration de la main-d'œuvre chez les nouveaux diplômés en soins infirmiers en Ontario. Une démarche de méthodes mixtes a été utilisée, notamment des questionnaires, des entrevues et des groupes de discussion. Les résultats indiquent que l'emploi à temps plein de nouveaux diplômés a augmenté au cours de la période étudiée et que le mentorat a facilité l'intégration de la main-d'œuvre chez les nouveaux diplômés en soins infirmiers.

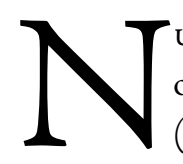

Urses constitute the largest healthcare profession in Canada, with over 340,000 registered nurses (RNs) and licensed practical nurses nationwide (CIHI 2010). In Ontario, licensed practical nurses are called registered practical nurses (RPNs). The nursing workforce has been vulnerable to economic fluctuations over the past 30 years. Healthcare restructuring during the late 1990s resulted in a decrease in the supply of nurses and a trend towards part-time (PT) employment (Blythe et al. 2001). Early studies tracked employment patterns of new graduate nurses in Ontario and demonstrated an increase in PT and casual employment (Alameddine et al. 2006; Baumann et al. 2006a; Grinspun 2007). The severe acute respiratory syndrome (SARS) outbreak in 2003 showed the province had little surge capacity to respond to the epidemic and highlighted the issue of PT and casual nursing staff throughout Ontario (Naylor 2003; Walker 2004; Baumann et al. 2006b).

In response to the PT trend, policy makers created the Nursing Graduate Guarantee (NGG) to stimulate full-time (FT) employment opportunities for new graduate nurses in Ontario. This paper presents the results of a study conducted over a three-year period to evaluate the NGG. The historical context for the development of the initiative is provided in a companion paper, "Policy to Practice: Collaboration in the Evolution of a Nursing Health 
Human Resources Policy" (Burkoski et al. 2011). The purpose of the current paper is to present facilitators and barriers to policy implementation and to assess the impact of the NGG on FT employment and workforce integration of new graduate nurses. Data were compared over time and summarized in annual reports (Baumann et al. 2008, 2009, 2010). Workforce integration is the process by which new graduates enter the workforce efficiently, effectively and with productive employment. It includes the opportunity for FT employment, being prepared for independent practice (skills and knowledge), adapting to the culture of an organization and integrating into the organizational system.

\section{Components of the Nursing Graduate Guarantee, 2007-2009}

To participate in the NGG, new graduate nurses and employers register on an online employment portal (HFO 2011). Once an employer offers a new graduate a job, funding is transferred to the employer to subsidize a temporary FT supernumerary (above staff complement) position for six months (MOHLTC 2008). Employers must provide graduates with a mentor for the duration of the position. After three months but before six months, employers are required "to use their best efforts" to transition new graduate nurses to permanent FT positions (MOHLTC 2008). If they are unable to offer a permanent FT position, employers must fund an additional six weeks of FT supernumerary employment.

\section{Purpose and objectives}

The purpose of this study was to examine facilitators and barriers to policy implementation and assess the impact of the NGG on FT employment and workforce integration of new graduate nurses in Ontario. Objectives were as follows:

- Identify demographics of nursing graduates.

- Describe the types of organizations that participated in the NGG.

- Identify barriers and facilitators to policy implementation.

- Identify employer perspectives about FT employment.

- Evaluate the impact of mentorship on the transition of new graduates to the workforce.

- Conduct a secondary analysis of the College of Nurses of Ontario's regulatory administrative database to examine changes in FT employment among new graduates.

\section{Methodology}

A mixed-methods approach (Tashakkori and Teddlie 2003) was used to examine the perspectives of employers, new graduates and union representatives. Data collection included online surveys, focus groups and interviews. The use of quantitative and qualitative methods to evaluate policy ensures that a study is well contextualized and policy relevant (White 2008).

Information on the employment status of new graduates was analyzed using new member data from the College of Nurses of Ontario's (CNO) regulatory administrative database. The database collects employment data on new member RNs and RPNs in Ontario on an 
annual basis. The $\mathrm{CNO}$ renewal form includes variables such as age, sex, employment status, type of employer, position in nursing, primary area of practice and practice location (i.e., geographic region). These data are available in published format approximately eight to nine months after original collection; thus, there is a time lag.

\section{Surveys}

Online surveys of new graduate nurses and employers were conducted in 2007, 2008 and 2009 using Surveymonkey. Because of the different graduation dates of the educational institutions involved in the study, data collection occurred over a three- to six-month period. An advisory board to the study suggested that union representatives should also be surveyed. This was done starting in 2008. In 2007, the new graduate survey was pilot tested for face and content validity using a convenience sample of 77 new graduates. Face and content validity were established for the employer survey by piloting it with five employers. The union survey was developed using data collected from semi-structured interviews with union leaders and stewards. The survey was then pilot tested for face validity with three union members.

The new graduate survey included demographic and employment data. It also included questions about the graduates' experiences with the mentorship component of the NGG and their overall satisfaction with the initiative. Employer survey questions focused on employers' satisfaction with the NGG, barriers to offering new graduates FT employment and overall perceptions of the effectiveness of the initiative. The union survey included questions about union perceptions of the NGG process, union-employer collaboration throughout the process and overall impressions of the initiative. Contact information for new graduates and employers was obtained through the employment portal registry (i.e., HFOJobs). Union representatives were contacted through the Ontario Nurses' Association database.

A letter of invitation with a link to the online survey was e-mailed to all new graduate nurses who registered on the employment portal across the three-year study period. The number of registrants each year was 2,761 (2007), 3,550 (2008) and 4,630 (2009). The employer survey was e-mailed to 296 participating employers in 2007, 301 participating employers in 2008 and 197 participating employers in 2009. An e-mail with a link to the online survey was sent to 433 union representatives in 2008 and 2009.

\section{Focus groups and individual interviews}

Semi-structured interview guides were developed for the employer focus groups and new graduate nurse interviews. The questions were sequenced according to the NGG process: hearing about the initiative, using the employment portal, hiring into the NGG, orientation/ mentorship and transitioning into permanent jobs. The employer and new graduate interview guides were aligned to capture perceptions from both groups on similar questions. 


\section{EMPLOYERS}

A sample of employers across sectors was chosen from participating organizations. Human resources managers and nurse administrators from these organizations were contacted by e-mail and invited to participate in a focus group. Semi-structured interview guides were used for the focus groups to ask employers about facilitators and barriers to NGG implementation and their ability to offer FT permanent positions to new graduates. The interviews were one hour long and were conducted via teleconference.

\section{NEW GRADUATES}

The sample of new graduates was obtained by asking survey respondents to provide contact information if they were willing to be interviewed. A convenience sample of new graduates who agreed was chosen from the list of e-mails provided. Graduates were selected across sectors and geographic locations. New graduates were asked about their experiences with mentoring and orientation, their perceptions of the strengths and weaknesses of the initiative and its effectiveness in transitioning them from school to the workplace. The interviews were one hour long and were conducted via teleconference.

\section{Data analysis}

Survey data were entered into PASW (version 18.0; SPSS Inc., Chicago, IL). Responses to each item were summarized using descriptive statistics. Frequency distributions were calculated on demographics. Employment status was examined using the $\mathrm{CNO}$ database of general class new member RNs and RPNs.

The employer focus groups and individual interviews conducted by telephone were audiotaped and transcribed. During data collection, the research team followed a sequence of interview, transcription, analysis, reflection and modification. Interviews were coded into QSR NVivo version 7.0 (QSR International Pty Ltd., Doncaster, Victoria, Australia). Texts were then interpreted through thematic analysis (Boyatzis 1998).

During the preliminary coding, each member of the research team coded several texts independently. Team members then collaborated to develop a refined scheme to code the texts. Additional codes were assigned as new themes emerged. Major themes were highlighted, and key findings were categorized appropriately under each thematic heading.

\section{Results}

\section{Response rates}

\section{NUMBER OF SURVEY RESPONDENTS}

The number of new graduate survey respondents was 1,780 in 2007, 998 in 2008 and 1,358 in 2009 (see Table 1 for response rates). The number of employer survey respondents was 230 in 2007, 254 in 2008 and 162 in 2009. The number of union representative respondents was 144 in both 2008 and 2009 . 
TABLE 1. Nursing Graduate Guarantee evaluation survey response rates, 2007-2009

\begin{tabular}{|c|c|c|c|c|c|c|c|c|c|}
\hline \multirow{2}{*}{$\begin{array}{l}\text { Name of } \\
\text { survey }\end{array}$} & \multicolumn{3}{|c|}{2007} & \multicolumn{3}{|c|}{2008} & \multicolumn{3}{|c|}{2009} \\
\hline & Total & Respondents & $\begin{array}{l}\text { Response } \\
\text { rate }\end{array}$ & Total & Respondents & $\begin{array}{l}\text { Response } \\
\text { rate }\end{array}$ & Total & Respondents & $\begin{array}{l}\text { Response } \\
\text { rate }\end{array}$ \\
\hline $\begin{array}{l}\text { New graduate } \\
\text { nurse survey }\end{array}$ & 2,761 & ।,780 & $64 \%$ & 3,550 & 998 & $28 \%$ & 4,630 & ।,358 & $29 \%$ \\
\hline $\begin{array}{l}\text { Employer } \\
\text { survey }\end{array}$ & 296 & 230 & $78 \%$ & 301 & 254 & $84 \%$ & 197 & 162 & $82 \%$ \\
\hline $\begin{array}{l}\text { Union } \\
\text { representative } \\
\text { survey* }\end{array}$ & - & - & - & 433 & 144 & $33 \%$ & 433 & 144 & $33 \%$ \\
\hline
\end{tabular}

* First union survey distributed in 2008-2009.

Source: Baumann et al. 2008, 2009, 2010.

During the study period, university and college programs were amalgamated. This change took place over three years. Although it did not affect overall intake of graduates in Ontario, it caused some organizational disruption in the schools. While the merger was occurring, schools took longer to respond, possibly affecting response rates. The study examined employment across sectors to obtain an estimate of the capacity to employ new graduates. Although there are 1,198 potential employers, over half are long-term care organizations that have limited employment capacity. The university teaching hospitals are fewer in number but have more beds, and each organization can hire anywhere from 100 to 200 nurses in a given year.

\section{NUMBER OF INTERVIEW AND FOCUS GROUP PARTICIPANTS}

The employer focus group sample included 21 groups involving 127 healthcare organizations (42 in 2007, 43 in 2008 and 42 in 2009) over the study period. Semi-structured interviews were conducted with 9 new graduates in 2007, 16 new graduates in 2008 and 18 new graduates in 2009. The numbers were small because the interviews were designed to supplement and clarify survey results.

\section{Description of sample}

\section{EMPLOYER SURVEY RESPONDENTS}

The majority of employers who responded to the survey were from acute care hospitals and long-term care facilities (see Table 2).

\section{NEW GRADUATE SURVEY RESPONDENTS}

Demographic information regarding new graduate survey respondents is presented in Table 3. Across the three years of the evaluation, the majority of survey respondents were RNs, female and under the age of 30 . 


\section{EMPLOYER FOCUS GROUP PARTICIPANTS}

In 2007, 24 hospitals, 6 long-term care facilities and 12 community organizations participated in the employer focus groups. In 2008, 24 hospitals, 7 long-term care facilities and 12 community organizations participated. In 2009, 23 hospitals, 8 long-term care facilities and 11 community organizations participated.

TABLE 2. Percentage of participating employer survey respondents by type of organization, 2007-2009

\begin{tabular}{|l|c|c|c|}
\hline \multirow{2}{*}{ Type of organization } & \multicolumn{3}{|c|}{ N (\%) } \\
\cline { 2 - 4 } & $\mathbf{2 0 0 7}$ & $\mathbf{2 0 0 8}$ & $\mathbf{2 0 0 9}$ \\
\hline Acute care hospital & $89(38.7)$ & $103(40.6)$ & $67(43.2)$ \\
\hline Long-term care facility & $92(40.0)$ & $91(35.8)$ & $48(31.0)$ \\
\hline Public health & $7(3.0)$ & $14(5.5)$ & $11(7.1)$ \\
\hline $\begin{array}{l}\text { Community (Community health centre, Community care access centre, } \\
\text { Mental health, Physician offices, Nursing agency, Hospice) }\end{array}$ & $24(10.4)$ & $12(4.7)$ & $10(6.5)$ \\
\hline $\begin{array}{l}\text { Other hospitals (Continuing complex care/Rehabilitation, Addiction and } \\
\text { mental health) }\end{array}$ & $16(7.0)$ & $11(4.3)$ & $9(5.8)$ \\
\hline $\begin{array}{l}\text { Other (Family health team, Combined acute and long-term care, } \\
\text { College/University) }\end{array}$ & $2(0.9)$ & $23(9.1)$ & $10(6.5)$ \\
\hline Total & $\mathbf{2 3 0 ( \mathbf { 1 0 0 . 0 } )}$ & $\mathbf{2 5 4} \mathbf{( 1 0 0 . 0 )}$ & $\mathbf{1 5 5 *}(\mathbf{1 0 0 . 0 )}$ \\
\hline
\end{tabular}

* Missing data $\mathrm{N}=7$.

Source: Baumann et al. 2008, 2009, 2010.

TABLE 3. Demographics of new graduate survey respondents, 2007-2009

\begin{tabular}{|c|c|c|c|}
\hline \multirow[t]{2}{*}{ Demographic variables } & \multicolumn{3}{|c|}{$\mathbf{N}(\%)$} \\
\hline & $\begin{array}{c}2007 \\
N=1,780\end{array}$ & $\begin{array}{c}2008 \\
N=998\end{array}$ & $\begin{array}{c}2009 \\
N=1,358\end{array}$ \\
\hline \multicolumn{4}{|l|}{ Nurse group } \\
\hline Registered nurse & I,095 (61.5) & $715(71.6)$ & $902(66.4)$ \\
\hline Registered practical nurse & $685(38.5)$ & $283(28.4)$ & $456(33.6)$ \\
\hline Total & $1,780(100.0)$ & $998(100.0)$ & $1,358(100.0)$ \\
\hline \multicolumn{4}{|l|}{ Gender } \\
\hline Female & I,66। (94.3) & $901(91.2)$ & ।,228 (91.2) \\
\hline Male & $100(5.7)$ & $86(8.8)$ & $119(8.8)$ \\
\hline Total & $1,76 \mid(100.0)$ & $987(100.0)$ & I,347 (100.0) \\
\hline \multicolumn{4}{|l|}{ Age category } \\
\hline$<19$ & $6(0.3)$ & $2(0.2)$ & $4(0.3)$ \\
\hline $20-29$ & ।, $189(67.0)$ & $672(67.6)$ & $934(68.8)$ \\
\hline $30-39$ & $406(22.9)$ & $192(19.3)$ & $270(19.9)$ \\
\hline $40+$ & $174(9.8)$ & $128(12.9)$ & $150(11.0)$ \\
\hline Total & $1,775(100.0)$ & $994(100.0)$ & $1,358(100.0)$ \\
\hline
\end{tabular}

Source: Baumann et al. 2008, 2009, 2010. 
NEW GRADUATE INTERVIEW PARTICIPANTS

In 2007, 6 RN and 3 RPN new graduates were interviewed. In 2008, 9 RNs and 7 RPNs were interviewed. In 2009, 11 RNs and 7 RPNs were interviewed.

\section{Survey findings}

\section{POTENTIAL BARRIERS TO FT EMPLOYMENT}

Employer survey respondents indicated that lack of funding and lack of FT vacancies for new graduate nurses were the two main barriers to offering FT employment. Working within an organization's collective agreement was also viewed as a potential barrier. If organizations placed new graduates into specialty areas through the NGG, they were able to gain six months of experience that would give them a competitive advantage over existing staff when applying for FT permanent positions. Union survey respondents were asked how often they believed this was happening in their organization. Results demonstrated that most did not believe it occurred frequently. For example, in 2009, over half (52\%) of union representatives surveyed indicated that new graduates never or almost never transitioned to a specialty position ahead of existing staff.

\section{Focus group and interview findings}

The major themes identified in the employer focus groups and individual interviews with new graduate nurses are categorized according to the objectives of the evaluation.

\section{FACILITATORS: EMPLOYER PERSPECTIVES}

Facilitators for employers differed across sectors, size of institution and geographical location. Employers in the focus groups reported sectoral and regional differences in the issues that affected how they integrated new graduates into their organizations. In general, employers in the public health focus group agreed that employees typically transition to public health through temporary contract positions. Long-term care employers were able to place only a few RPNs into FT positions but reported having RN vacancies because of a lack of interest in the sector. There is some variability in how successful organizations in the community sector have been in offering FT positions.

One of the facilitators to FT employment is size of institution. Larger acute care sites were more likely to transition graduates to regular FT positions after three months of their supernumerary position. However, small rural hospitals did not have the capacity to absorb supernumerary positions. They were also limited in the number of FT positions they could offer new graduates because existing PT staff with more seniority were waiting for FT positions.

Another facilitator was the use of resource teams. Float pools and resource teams are strategies that schedule one individual across different clinical units to meet service requirements as needed. In this study, larger acute care sites created resource pools and were generally more readily able to offer FT positions. To make these positions more attractive, some sites developed float pools that were based on home units requiring nurses to float to two or three units that were created as pods of similar areas such as cardiology, cardiac surgery and vascular 
surgery (Baumann et al. 2008). It was reported that use of a resource team helped rural hospitals offer FT positions. Other strategies included collapsing vacant PT positions in acute care to create FT lines and developing FT positions across sites.

\section{BARRIERS: EMPLOYER PERSPECTIVES}

Employers were asked about the adequacy of the applicant pool on the NGG portal. Responses varied by sector. Employers in acute care were generally satisfied and indicated they received a good response from the portal. Employers in rural areas reported having a good pool of applicants, which they attributed to the NGG and to other government initiatives targeting rural areas. However, employers in public health and long-term care indicated they would have liked more applicants. One long-term care employer said, "We interviewed a number of applicants. But before we made the job offer, they had already committed elsewhere.... we didn't get as many as we had hoped for." A community sector employer commented, "As long as we're competing with the hospital sector that pays a significant difference, we're going to be challenged."

Employers indicated that creating supernumerary positions required planning and collaboration between human resources and nurse administrators. Balancing resources and the intent of the initiative throughout its various stages was difficult. One challenge that arose in the early years of the initiative was that RN graduation occurred primarily in the spring, when organizations needed to grant their FT staff summer vacations. This reduced the availability of mentors to participate in the extended orientation. By the third year of the evaluation, many employers adapted their new graduate hiring strategies by staggering intake of new graduates over a few months.

\section{IMPLEMENTATION OF THE SIX-MONTH ORIENTATION AND MENTORING}

According to the employers, the mentoring model was one-to-one supervision. In some cases, graduates rotated out of the main unit to other areas of choice, where they were supervised by secondary mentors who reported to the primary mentor. Graduates found this approach helpful because of the increased exposure to various clinical areas.

Employers reported sector-specific differences related to mentoring. In the hospital sector, the mentor could remain on the unit with the new graduate while performing other unit responsibilities. Under these circumstances, the mentor was available to gradually transition the new graduate to an independent role. In the community and public health sectors, a one-to-one model limited the number of new graduates that an organization could hire. Where home visits were made, the mentor directly oversaw the new graduate. This model of supervision can affect the productivity of the mentor. One community employer stated, "Supernumerary works really, really well in the hospital sector ... in [the] community [sector], the mentor must be with the new graduate at all times." Even if the new graduate is taking the lead during home visits, the mentor must still be present. 


\section{IMPACT OF THE SIX-MONTH ORIENTATION AND MENTORING}

Employers and new graduates agreed that extended orientation and mentoring was a major advantage of the NGG. One new graduate stated, "It was great for me because I didn't feel I was ready to start nursing. I wouldn't have gone to a teaching acute care hospital to start working on my own; ... I wouldn't have had the confidence." Employers expressed similar sentiments about the benefits of mentoring: "You do get very high calibre ... [nurses] out of this [model] ... once they have been mentored, they ... are much stronger."

When asked what motivated them to participate in the initiative, the majority of new graduates indicated they were interested because of the opportunity for FT work. However, having a mentor available to support their transition from school to the workplace was an additional benefit. Employers agreed that the mentoring component of the initiative made a major contribution to the transition of new graduates to the workplace. Employers in healthcare sectors where FT jobs were scarce still believed that the NGG benefited new graduates and helped prepare them for work.

\section{Changes in FT employment status over three years: $\mathrm{CNO}$ administrative database}

Figure 1 presents the analysis of FT employment of CNO new member RNs and RPNs from 2006 to 2010. As noted, the CNO collects regulatory data once a year on all RNs and RPNs in the province. Employment data about new members are analyzed and reported separately in the annual membership statistics reports. Between 2006 and 2010, FT employment increased from $59 \%$ to $71 \%$ for RNs and from $24 \%$ to $36 \%$ for RPNs.

FIGURE 1. Full-time employment of general class new members (RNs and RPNs), 2006-20I0

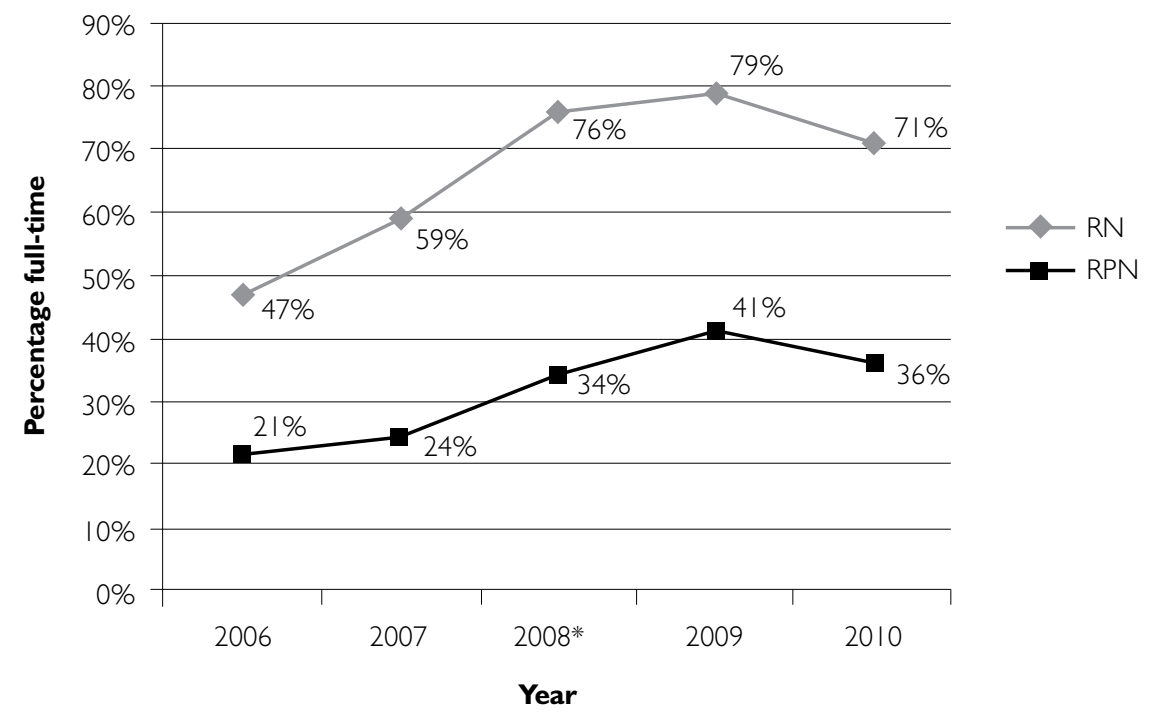

\footnotetext{
* College of Nurses of Ontario 2008 new members were the first cohort of Nursing Graduate Guarantee participants.

Note: Date of employment data reflects new graduates from the previous year. New graduates who registered with the College of Nurses of Ontario in 2007 were not reported until 2008. Similarly, graduates from 2008 were reported in 2009, and graduates from 2009 were reported in 2010. Source: College of Nurses of Ontario Membership Statistics Report 2009, 2010.
} 


\section{Discussion and Conclusions}

The purpose of this paper was to report on facilitators and barriers to policy implementation and assess the impact of the NGG on FT employment and workforce integration of new graduate nurses in Ontario. Other than a report on the supply and employment of new nursing graduates in Ontario and their absorption into the workforce from 2003 to 2005 (Baumann et al. 2006a), the authors are not aware of any other efforts to evaluate similar types of programs and economic incentives nationally or internationally. The NGG policy is a unique FT employment initiative in Canada. There are new graduate transition programs in other provinces, but they are at the regional level only and are not a substantial economic stimulus for FT employment.

Findings from the study indicate that the NGG was successful over a three-year period in stimulating FT employment opportunities for new graduates across all healthcare sectors. Many employers in the focus groups reported hiring new graduates specifically because of the NGG. Compared to cohorts entering the workforce prior to the NGG, an increased number of new graduates obtained FT employment following implementation of the policy in 2007 (Baumann et al. 2006a).

Analysis of the $\mathrm{CNO}$ administrative database confirmed an increase in FT employment of new member RNs and RPNs between 2006 and 2009. This was followed by a slight decrease for both groups in 2010. The drop in FT employment from 2009 to 2010 could be the result of a number of factors. It might reflect employment trends in other sectors or may be a phenomenon specific to the healthcare sector. For example, statistics demonstrated that between 2008 and 2009 there was a loss of 400,000 jobs nationally, which resulted in an increase in the unemployment rate from 6.3\% in 2008 to 8.6\% in 2009 (LaRochelle-Côté and Gilmore 2009). The greatest loss occurred in younger age groups. However, it is important to note that in this provincial study, there was a slight drop in FT in 2010, but FT employment was maintained at $70 \%$ for RNs and close to $40 \%$ for RPNs over the three-year study period.

For organizations participating in the NGG, this slight downturn in the last year could be indicative of a couple of issues. It could indicate an economic downturn or could more likely be the result of hiring large numbers of new graduates in the early years of the initiative, thereby reducing the demand for FT employees. Given the preference of new graduates for FT work, ongoing examination of future employment practices is warranted to gain a fuller understanding of all the issues that deter employers from offering FT positions.

In conclusion, according to stakeholders, the benefits of the initiative outweigh the implementation challenges. Major strengths of the NGG include FT employment and the opportunity for graduate nurses to have a mentor for up to six months to help them transition from school to the workplace. The supportive environment of mentorship gave new graduates time to build the confidence needed to practise independently. Employers benefited by receiving funding for six months. Future research is planned to study the impact of the NGG on longterm retention of new nurses in Ontario. 
There are several limitations to a study of this kind. Data could not be collected at one point in time because the NGG program allowed employment access up to six months after graduation. Additionally, data collection had to be inclusive of the differing graduation dates within any given year. Surveys were administered via e-mail and were completed on a voluntary basis. Surveys, interviews and focus groups are subject to volunteer bias and may not reflect the experience of all new graduate nurses, employers and union representatives in integrating new graduate nurses into the workforce.

Correspondence may be directed to: Andrea Baumann, RN, PhD, Associate Vice President, International Health, Faculty of Health Sciences, McMaster University, Director, Nursing Health Services Research Unit (McMaster University site), 1200 Main Street West, MDCL 3500, Hamilton, ON L8N 3Z5; tel.: 905-525-9140, ext. 22281; fax: 905-522-5493; e-mail: baumanna@mcmaster.ca.

\section{REFERENCES}

Alameddine, M., A. LaPorte, A. Baumann, L. O’Brien-Pallas, B. Mildon and R. Deber. 2006. “Stickiness and Inflow as Measures of the Relative Attractiveness of Various Sub-Sectors of Employment." Social Science and Medicine (63)9: 2310-19.

Baumann, A., J. Blythe, K. Cleverley, D. Grinspun and C. Tompkins. 2006a. Health Human Resources Series Number 2. Educated and Underemployed: The Paradox for Nursing Graduands. Hamilton, ON: Nursing Health Services Research Unit, McMaster University.

Baumann, A., J. Blythe and J. Underwood. 2006b. "Surge Capacity and Casualization: Human Resources Issues in the Post-SARS Health System." Canadian Journal of Public Health 97(3): 230-32.

Baumann, A., M. Hunsberger, D. Idriss, M. Alameddine and D. Grinspun. 2008. Health Human Resources Series Number 10. Employment of Nursing Graduates: Evaluation of a Provincial Policy Strategy. Hamilton, ON: Nursing Health Services Research Unit, McMaster University.

Baumann, A., M. Hunsberger, D. Idriss-Wheeler and M. Crea-Arsenio. 2009. Health Human Resources Series Number 19. Employment Integration of Nursing Graduates: Evaluation of a Provincial Policy Strategy Nursing Graduate Guarantee 2008-2009. Hamilton, ON: Nursing Health Services Research Unit, McMaster University.

Baumann, A., M. Hunsberger and M. Crea-Arsenio. 2010. Health Human Resources Series Number 27. Employment Integration of Nursing Graduates: Evaluation of a Provincial Policy Strategy Nursing Graduate Guarantee 2009-2010. Hamilton, ON: Nursing Health Services Research Unit, McMaster University.

Blythe, J., A. Baumann and P. Giovannetti 2001. "Nurses' experiences of restructuring in three Ontario hospitals." Journal of Nursing Scholarship 33(1): 61-68.

Boyatzis, R. 1998. Transforming Qualitative Information: Thematic Analysis and Code Development. Thousand Oaks, CA: Sage.

Burkoski, V., J. Tepper and S. Matthews. 2011. "Policy to Practice: Collaboration in the Evolution of a Nursing Health Human Resources Policy”. Healthare Policy 7(2): 32-9.

Canadian Institute for Health Information (CIHI). 2010. Regulated Nurses: Canadian Trends, 2004-2008.

Ottawa: Author.

College of Nurses of Ontario (CNO). 2009. Membership Statistics Report 2009. Toronto: Author.

College of Nurses of Ontario (CNO). 2010. Membership Statistics Report 2010. Toronto: Author.

Grinspun, D. 2007. "Healthy Workplaces: The Case for Shared Clinical Decision-Making and Increased Full-Time Employment." Healthcare Papers 7: 85-91. 


\section{Workforce Integration of New Graduate Nurses}

HealthForceOntario (HFO). 2011. Nursing Graduate Guarantee Overview: The Nursing Graduate Portal. Retrieved October 24, 2011. <http://www.healthforceontario.ca/Work/InsideOntario/OntarioNurses/ NursingGradGuarantee/Overview.aspx $>$.

LaRochelle-Côté, S. and J. Gilmore. 2009. “Canada’s Employment Downturn.” Perspectives, Statistics Canada Catalogue no. 75-001-X.

Ministry of Health and Long-Term Care (MOHLTC). 2008. Guidelines for Participation in the Nursing Graduate Guarantee. Retrieved March 18, 2009. <http://www.healthforceontario.ca/upload/en/work/2009_01_09_ngg_ participation\%20guidelines.pdf $>$.

Naylor, D. 2003. Learning from SARS. Renewal of Public Health in Canada. Ottawa: Health Canada.

Tashakkori, A. and C. Teddlie. 2003. Handbook of Mixed Methods in Social and Behavioural Research. Thousand Oaks, CA: Sage.

Walker, D. 2004. For the Public's Health: A Plan of Action, Final Report. Expert Panel on SARS and Infectious Disease Control. Toronto: Ministry of Health and Long-Term Care.

White, H. 2008. Network of Networks on Impact Evaluation (NONIE). Working Paper No. 7. Of Probits and Participation: The Use of Mixed Methods in Quantitative Impact Evaluation. Retrieved September 30, 2011. <http:// www.worldbank.org/ieg/nonie/docs/WP7_White.pdf>. 